\title{
RNA nanotechnology breakthrough for targeted release of RNA- based drugs using cell-based aptamers
}

Sohameh Mohebbi ${ }^{1}$, Nahid Bakhtiari $^{2}$, Fahimeh Charbgoo ${ }^{3}$, Zeinab Shirvani-Farsani ${ }^{4}$

${ }^{1}$ Department of Biotechnology, Ale-Taha Institute of Higher Education, Tehran, Iran

${ }^{2}$ Department of Biotechnology, Iranian Research Organization for Science and Technology, Tehran, Iran

${ }^{3}$ Department of Pharmaceutical Biotechnology, School of Pharmacy, Mashhad University of Medical Sciences, Mashhad, Iran

${ }^{4}$ Department of Cellular and Molecular Biology, Faculty of Life Sciences and Technology, Shahid Beheshti University G.C., Tehran, Iran

\begin{abstract}
Nucleic acids play different roles besides storing information and proteins coding. For example, singlestranded nucleic acids can fold into complicated structures with capability of molecular detection, catalyzing bioreactions and therapy. The development of RNA-based therapies has been rapidly progressed in the recent years. RNA aptamers are biomolecules with a size of 10 to $50 \mathrm{~nm}$ that can be useful for targeted therapy and systemic release of therapeutics into the desired tissues. Aptamers can be linked to other RNA drugs and form a biohybrid RNA nanostructure. The chemical nature of the aptamers makes them attractive therapeutic agents compared to other small molecules and antibodies. In this review, we discuss different approaches related to drug targeting and release by RNA aptamers, since the importance of the aptamer-based nanomedicine is now well demonstrated and this field become a promising platform in the treatment of diseases.
\end{abstract}

Keywords: Aptamer, RNA-based therapies, Nano-medicine, Nanoparticles.

Cited as: Mohebbi S, Bakhtiari N, Charbgoo F, Shirvani-Farsani Z. RNA Nanotechnology breakthrough for targeted release of RNA-based drugs using cell-based aptamers, Medical Science Journal of Islamic Azad University, Tehran Medical Branch 2019; 29(4): 275-283.

Correspondence to: Nahid Bakhtiari

Tel: +989122812960

E-mail: nbakhtiari@irost.org

ORCID ID: 0000-0002-9262-4341

Received: 27 Aug 2018; Accepted: 13 Nov 2018 
مجله علوم يزشكى دانشَاه آزاد اسلامى

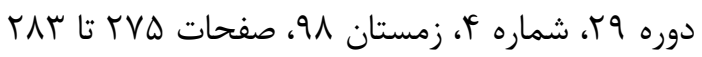

Review

Article

\section{تلفيق آيتامرها با فناورى RNA}

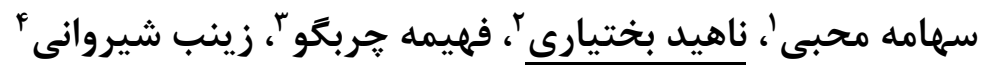

'دكتراى نانوبيوتكنولوزى، استاديار كروه بيوتكنولوزى، موسسه آموزش عالى آل طه

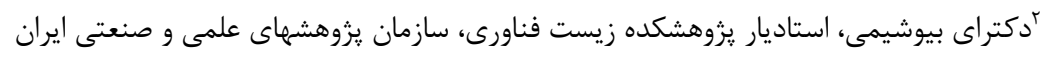

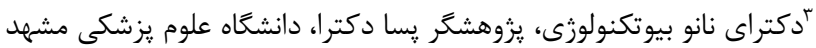

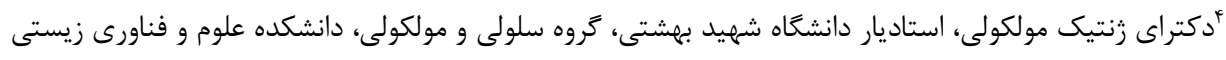

\section{جكيده}

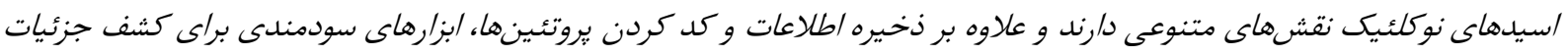

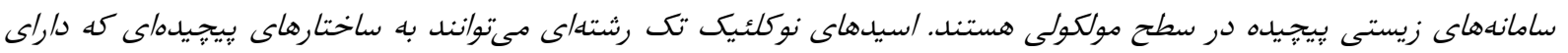

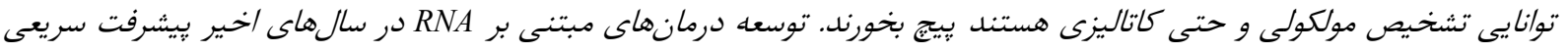

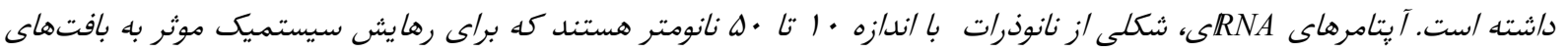

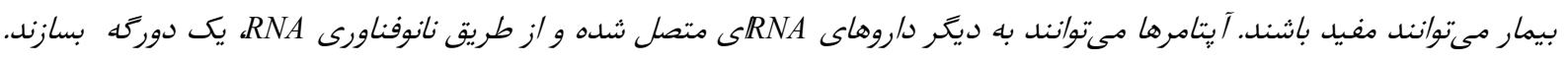

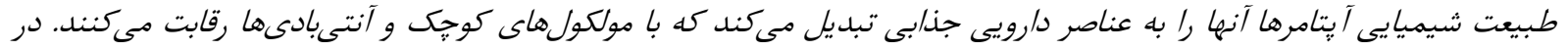

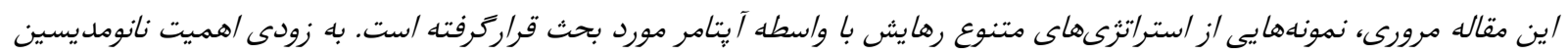

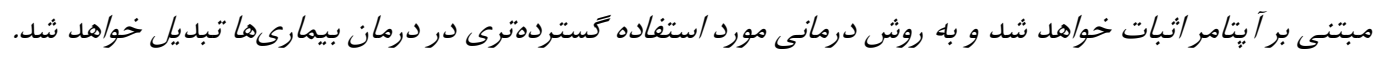

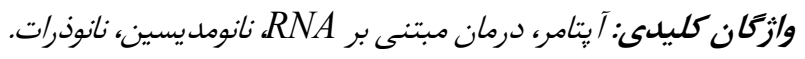

رشتهاى مىتوانند به ساختارهاى پيِجيده با توانايى تشخيص

مقدمه

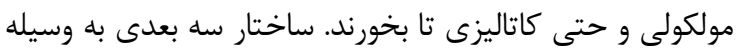

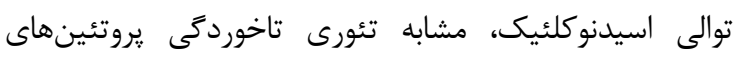

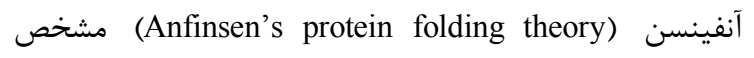

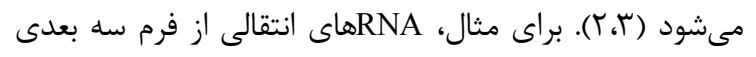

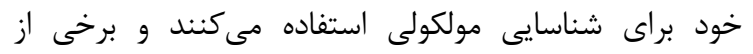
هاى ريبوزومى مىتوانند مرحله كليدى در مسير سنتز

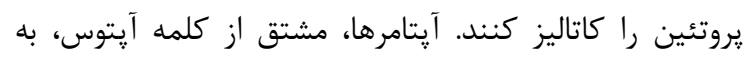

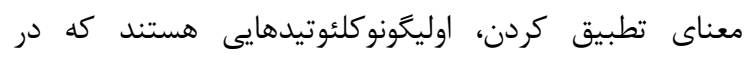

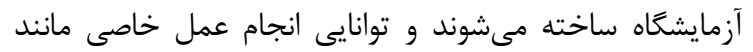

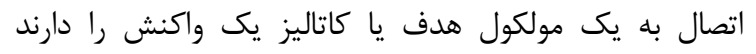

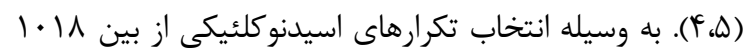

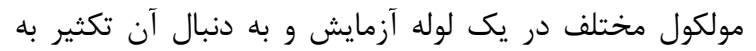

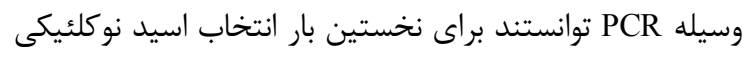

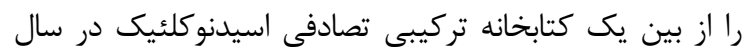
مفهوم استفاده از آيتامرها بهعنوان ابزار دارورسانى، از اصطلاح

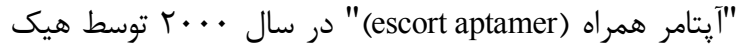

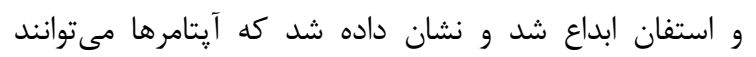

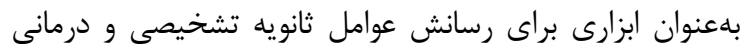
به كار روند (1). با ظهور تكنيكهاى زيستشناسى مولكولى، رألى

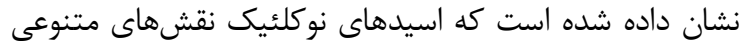

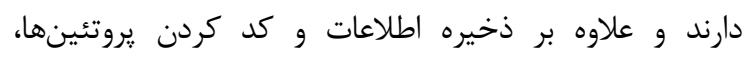
ابزارهاى سودمندى براى كشف جزئيات سامانههاى زيستى درنى پيجحيده در سطح مولكولى هستند؛ اسيدهاى نوكلئيك تك

\footnotetext{
أدرس نويسنده مسئول: سازمان يُروهشهاى علمى و صنعتى ايـران، يُروهشكده زيسـت فناورى ناهيــ (email: nbakhtiari@irost.org) بختيارن ORCID ID: 0000-0002-9262-4341 تاريخ دريافت مقاله: QV//9/0

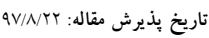


يكى از استفادههاى نوآورانه از آنها اين است كه به عنوان حامل دارو براى درمان هدفمند سلول يا بافت خاص مورد

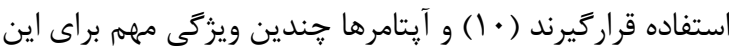
منظور خاص را ارائه مى كنند (1) (1). اول اينكه، آيتامرها تشكيل ساختارهاى سه بعدى پايدار مى دهند كه مىتوانند بسيار متمايز باشند و به طور خاص به اهداف مولكولى خود متصل شوند؛ زيرا ساختار فضايى آنها در محيط داخل بدن باقى مىماند (II).

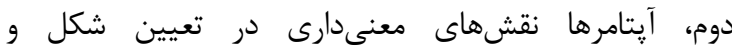
استوكيومترى بازى مىكنند. برخلاف آنتى بادى، اسيدهاى نوكلئيك مىتواند در يك مد بسيار قابل برنامهريزى و قابل پيش بينى خود تجمع ذاتى داشته باشند تا حلقههاى مختلف و
•199 نشان دهند (ه، أ). تنوع بسيار زياد مولكولهاى اسكرين

شده به اين روش به كشف مولكولهايى منجر شده است كه

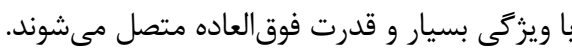

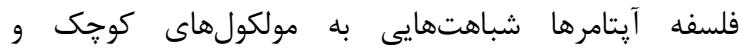
آنتىبادىهاى درمانى دارد (1-و). طبيعت شيميايى آيتامرها آنها را به عناصر دارويى جذابى تبديل ميى كند كه با مولكولهاى كوجى و آنتىبادىها رقابت مى كنند. مشابه مهار, كنندههاى سنتى كوجى مولكول، از قبيل داروهاى يرفروش وياگرا، گليوى و تامىفلو، آيتامرها در شكاف مناسب در سطوح يروتئين، به خصوص سايتهاى فعال آنزيم براى مهار فعاليت آن جفت

مى شوند (9). (9) (1) (1)

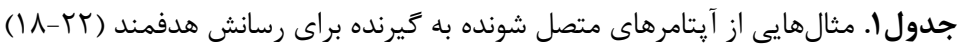

\begin{tabular}{|c|c|c|c|}
\hline Cell surface target & Oligo & Cargo & Reference \\
\hline $\begin{array}{l}\text { Prostate-specific } \\
\text { membrane antigen }\end{array}$ & RNA aptamer & Anti-Lamin A/C siRNA & $\begin{array}{l}\text { Chu et al. } \\
\text { (2006b) }\end{array}$ \\
\hline $\begin{array}{l}\text { Prostate-specific } \\
\text { membrane antigen }\end{array}$ & RNA aptamer & $\begin{array}{l}\text { Polo-like kinase } 1 \text { (PLK1) and } \\
\text { BCL2 siRNA }\end{array}$ & $\begin{array}{l}\text { McNamara et al. } \\
\text { (2006) }\end{array}$ \\
\hline $\begin{array}{l}\text { Prostate-specific } \\
\text { membrane antigen }\end{array}$ & RNA aptamer & $\begin{array}{l}\text { Eukaryotic elongation factor } \\
2 \text { (EEF2) siRNA }\end{array}$ & $\begin{array}{l}\text { Wullner et al. } \\
\text { (2008) }\end{array}$ \\
\hline $\begin{array}{l}\text { Prostate-specific } \\
\text { membrane antigen }\end{array}$ & RNA aptamer & $\begin{array}{l}\text { Polo-like kinase } 1 \text { (PLK1) } \\
\text { siRNA }\end{array}$ & $\begin{array}{l}\text { Dassie et al. } \\
\qquad(2009)\end{array}$ \\
\hline $\begin{array}{l}\text { Prostate-specific } \\
\text { membrane antigen }\end{array}$ & RNA aptamer & Gelonin (toxin) & $\begin{array}{l}\text { Chu et al. } \\
\qquad(2006 \mathrm{a})\end{array}$ \\
\hline $\begin{array}{l}\text { Prostate-specific } \\
\text { membrane antigen }\end{array}$ & RNA aptamer & Doxorubicin (cancer drug) & $\begin{array}{l}\text { Bagalkot et al. } \\
\qquad(2006)\end{array}$ \\
\hline $\begin{array}{l}\text { Prostate-specific } \\
\text { membrane antigen }\end{array}$ & RNA aptamer & $\begin{array}{l}\text { Cisplatin (cancer drug, } \\
\text { encapsulated in aptamer- } \\
\text { coated nanoparticle) }\end{array}$ & $\begin{array}{l}\text { Dhar et al. } \\
\qquad(2008)\end{array}$ \\
\hline $\begin{array}{l}\text { Prostate-specific } \\
\text { membrane antigen }\end{array}$ & RNA aptamer & $\begin{array}{l}\text { Docetaxel (cancer drug, } \\
\text { encapsulated in aptamer- } \\
\text { coasted nanoparticle) }\end{array}$ & $\begin{array}{l}\text { Farokhzad et al. } \\
\qquad(2006)\end{array}$ \\
\hline $\begin{array}{l}\text { Prostate-specific } \\
\text { membrane antigen }\end{array}$ & RNA aptamer & $\begin{array}{l}\text { Super-paramagnetic iron oxide } \\
\text { (encapsulated in aptamer- } \\
\text { coated nanoparticle for } \\
\text { diagnostic use) }\end{array}$ & $\begin{array}{l}\text { Wang et al. } \\
\qquad(2008)\end{array}$ \\
\hline Nucleolin & $\begin{array}{l}\text { DNA aptamer } \\
\text { (AS1411) }\end{array}$ & $\begin{array}{l}\text { Cisplatin (cancer drug, } \\
\text { encapsulated in aptamer- } \\
\text { coated liposome) }\end{array}$ & $\begin{array}{l}\text { Cao et al. } \\
(2009)\end{array}$ \\
\hline Nucleolin & $\begin{array}{l}\text { DNA aptamer } \\
\text { (AS1411) }\end{array}$ & $\begin{array}{l}\text { TMPyP4 (photodynamic } \\
\text { therapy) }\end{array}$ & $\begin{array}{l}\text { (Shieh et al. } \\
2010)\end{array}$ \\
\hline $\begin{array}{l}\text { HIV glycoprotein } \\
\text { (gp) } 120\end{array}$ & RNA aptamer & Tat/Rev siRNA, CD4 siRNA & $\begin{array}{l}\text { Zhou et al. } \\
\qquad(2008,2009)\end{array}$ \\
\hline $\begin{array}{l}O \text {-glycan-peptide } \\
\text { marker on } \\
\text { cancer cells }\end{array}$ & DNA aptamer & $\begin{array}{l}\text { Chlorin } e_{6} \\
\text { (photodynamic therapy) }\end{array}$ & $\begin{array}{l}\text { Ferreira et al. } \\
\qquad(2009)\end{array}$ \\
\hline $\begin{array}{l}\text { Mouse transferrin } \\
\text { receptor }\end{array}$ & $\begin{array}{l}\text { DNA and } \\
\text { RNA } \\
\text { aptamers }\end{array}$ & $\begin{array}{l}\alpha \text { - } L \text {-iduronidase } \\
\text { (a lysosomal enzyme for } \\
\text { enzyme replacement } \\
\text { therapy) }\end{array}$ & $\begin{array}{l}\text { Chen et al. } \\
\text { (2008) }\end{array}$ \\
\hline
\end{tabular}


siRNA هدفمند بدهند (ها). در اصل، اهداف سطحى سلول ممكن است

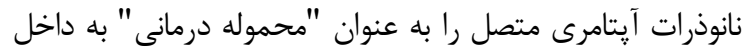
سلول منتقل كنند؛ در نتيجه سبب تسهيل اثر درمانى در سلولهاى هدف شوند. در حالى كه سلولهاى غير هدف ترني ترنين

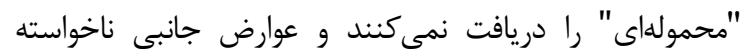
مىتواند به حداقل برسد. تعدادى از آيتامرهاى واردشده به سلول،
ساختارهاى متنوع ترموديناميكى پايدار را با استفاده از هر دو نوع

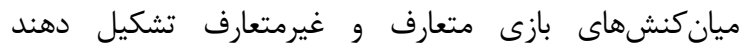

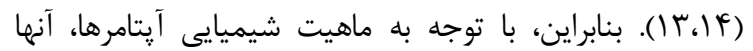
يتانسيل فوق العادهاى براى تشكيل بلوكهاى ساختمانى براى

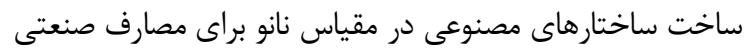

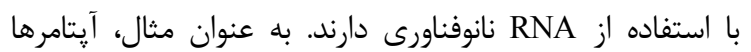

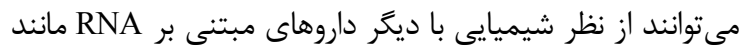

A Non-covalent aptamersiRNA conjugates

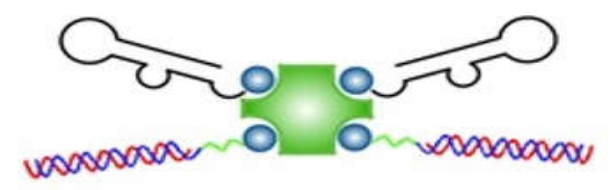

B Non-covalent aptamernanocarrier conjugates
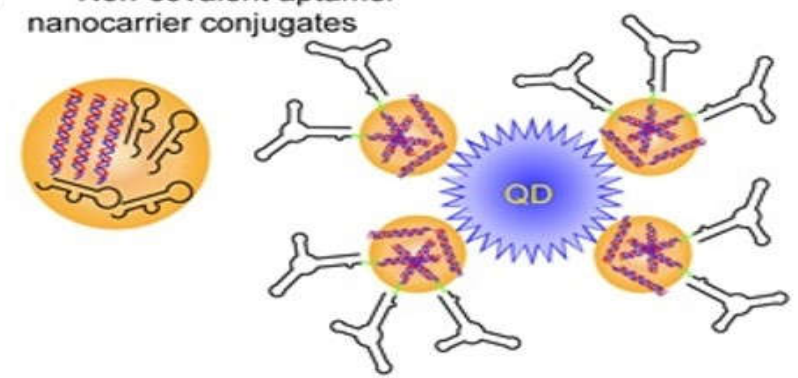
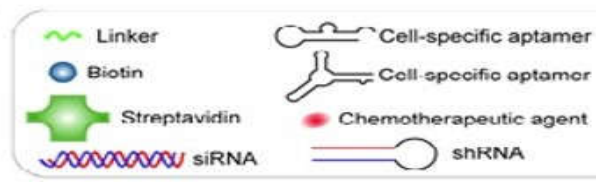

Nano-sized polymer polyethyleneimine, dendrimer

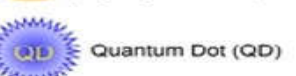

شكل ا. رهايش RNAi با واسطه آيتامر در درمان سرطان. (A) نمايى از كانثوكه siRNAآيتامر كه به صورت غير كوالان متصل شده اند. آيتامرهاى ويزه

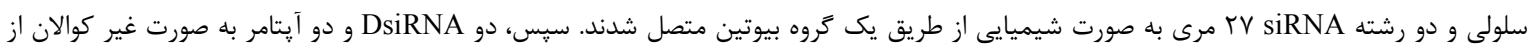

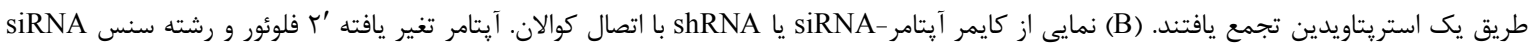

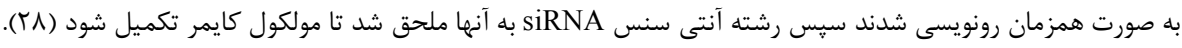

a

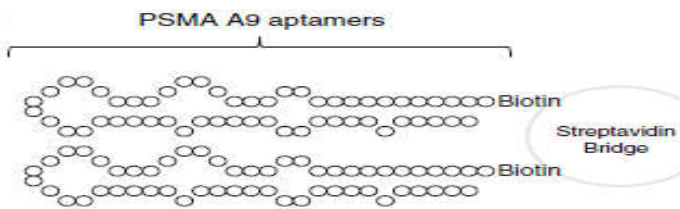

b $\overbrace{000000}^{\text {PSMA A10 aptamers }} \overbrace{000000000000000000000000000000000000000}^{21 \text { mer Bcl2 or Plk1 siRNA }}$

c

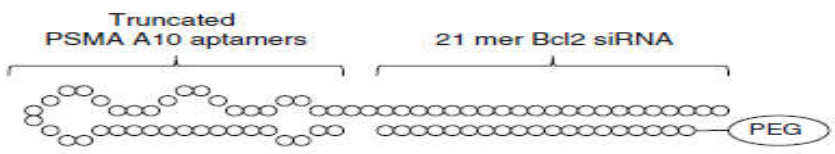

d

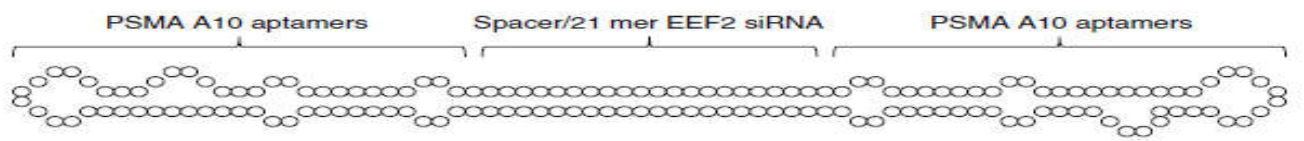

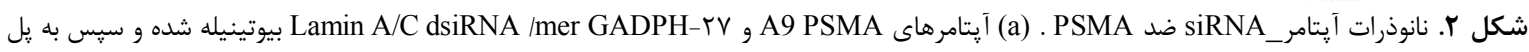

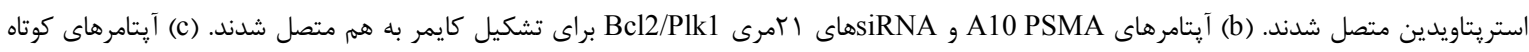

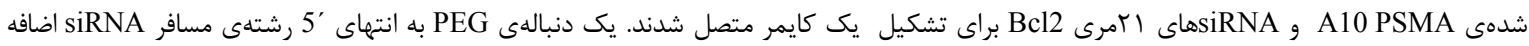

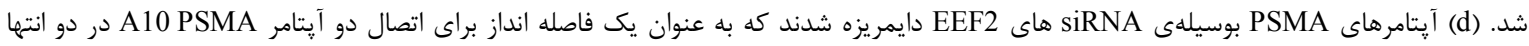
عمل مى كند. 
ماكرومولكولهاى بيولوزيكى، شامل DNA، RNA و يروتئينها،

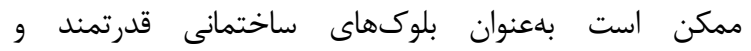
منحصربهفرد براى مونتاز از يايين به بالاى ساختارهاى نانو إنو و نانو

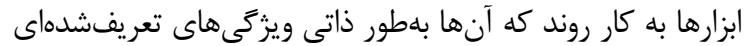

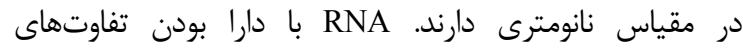

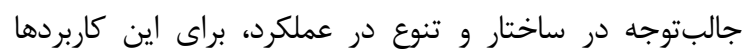
مناسب است. RNA مىتواند طراحى شود و با يك سطحى از

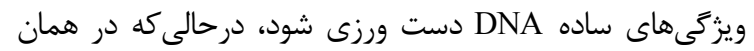
زمان يبحيدگى در ساختار و عملكرد مشابه يروتئينها راد اد داراست.

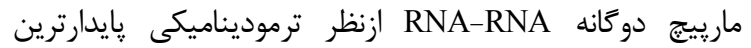
مارييج در بين سه ماريبج RNA و RNA-DNA RNA-RNA

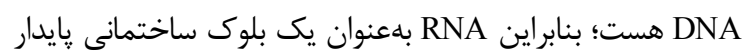
جهت ساخت نانو ذرات RNA براى شرايط و كاربردهاى مختلف به كاربرده مىشود. در دهلهاى كذشته، انواع مختلف مولكول

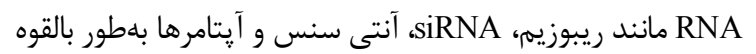

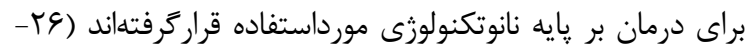

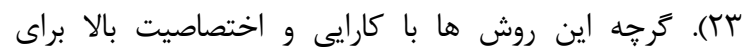
خاموش كردن بيان زن ها در شرايط برون تنى استفاده مىشود

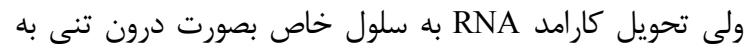

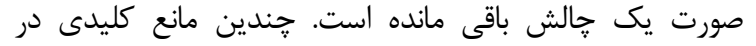

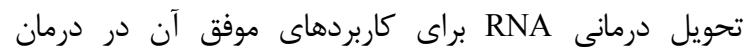

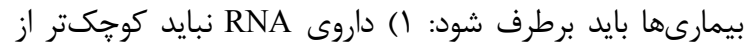

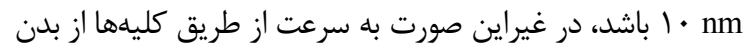

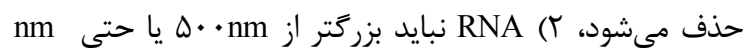

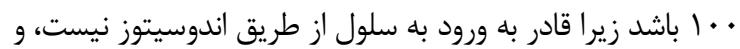

شناسايى، و به دليل ميل تركيبى و اختصاصيت بالا و امكان كانزو گه شدن شيميايى، بهطور ويزه براى تحويل هدفمند طيف كسترداى از كونهاى مولكولى (بهعنوانمثال، SiRNA ها و و

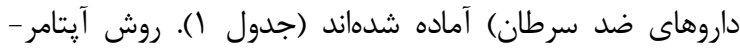

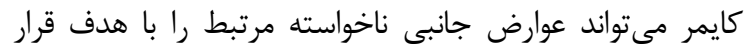

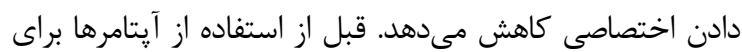
رسانش هدفمند، آنتىبادىها نقش مشابهى درآوردن عوامل ثانويه

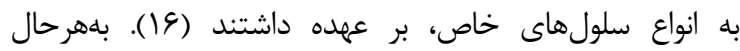

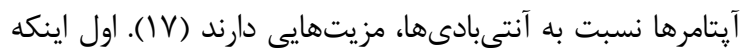

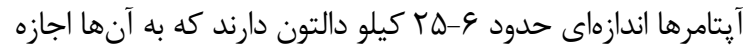

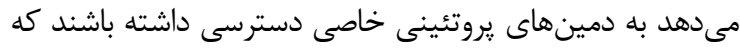

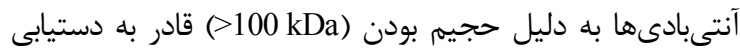
به آن نيستند. آرجه فرآيند ورود آتِامر به يروتئينهاى هدف

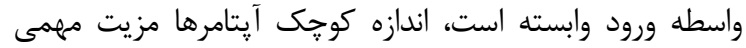
محسوب مىشود و اجازه مىدهد در مقايسه با آنتىبادىها، مولكولهاى بيشترى به يروتئين هدف متصل شوند؛ درنتيجه

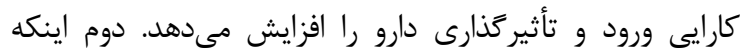

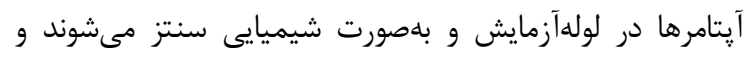
رابطه ساختار فعاليت ثابتى دارند. اين ويزّكى به آيتامرها اجازه مى دهد به طيف وسيعى از محمولهها شامل siRNA، داروها،

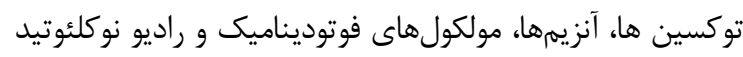

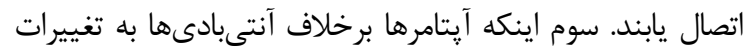

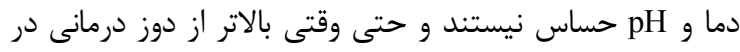

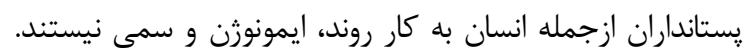

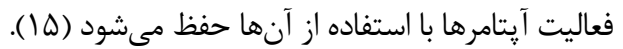

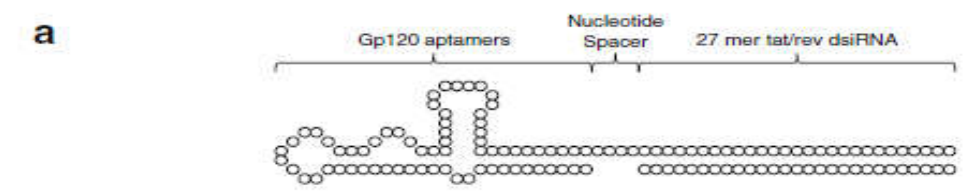

b

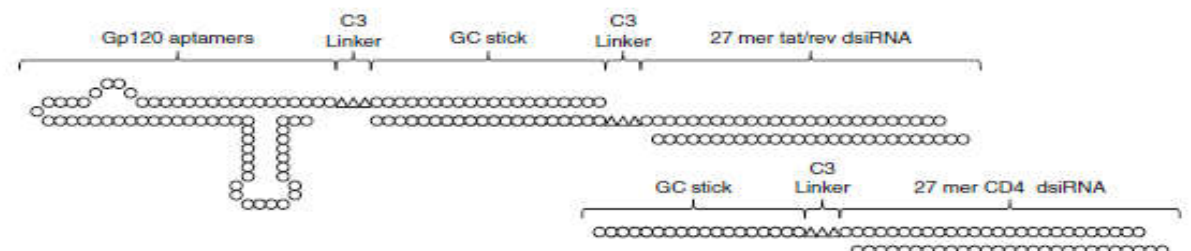

$00000000000000000000 \mathrm{~m}$ N 0000000000000000000000000000000000000000000000000

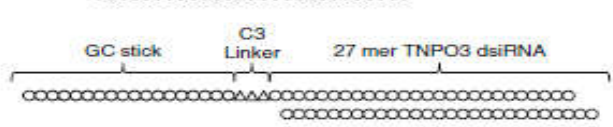

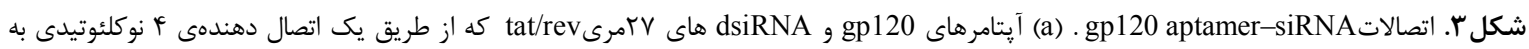

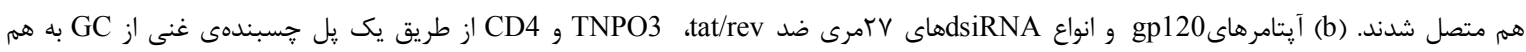




\section{HIV1 با واسطه آيتامر براى درمان RNAi}

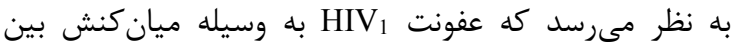

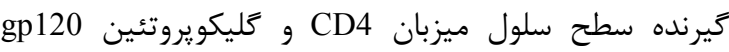
يوشش خارجى ويروس آغاز مىشود و دريى آن منجر به ادغان

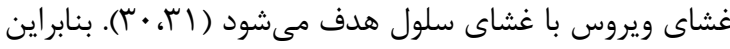
هم CD4 و هم gp120 اهداف اوليه براى درمان HIV1 هستند. بر همين اساس، گروهى از محققين مدلى را طراحى كردند كه

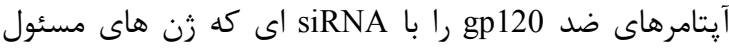

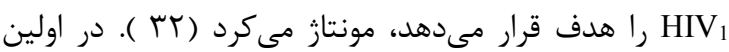

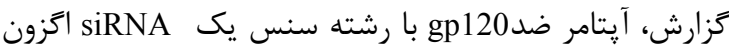

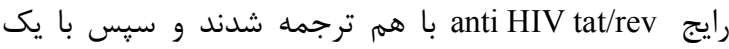
رشته آنتى سنس تغيير شكل نيافته مكمل anti HIV tat/rev siRNA- هيبريد شدند (شكل riRNA

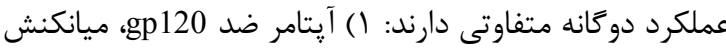

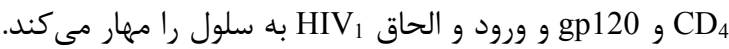
Tat بnti HIV tat/rev siRNA (Y و ر ا خاموش مى Rev رند و در نتيجه نسخه بردارى زنوم ويروس را مهار مى كند.

Her2 با واسطه آيتامر ضي كند

جين ترند و همكارانش، كانثوكه آيتامر Bc12 siRNA-Her2 را براى درمان سرطان سينه به كار بردند (TY). Her2 يكى

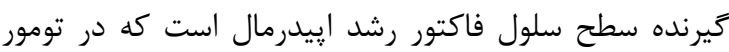

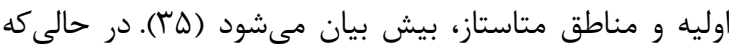
يc12 تركيبات شيميايى را در سلولهاى سرطان سينه انسانى مهار

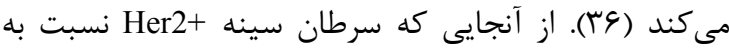
سلول هاى سرطانى فاقد Her2، پِيشروندهتر و مقاومتر به

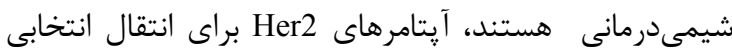

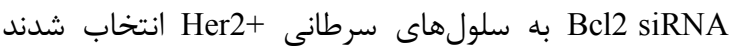

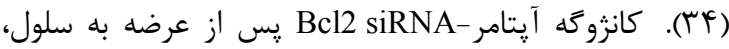
به طور اختصاصى وارد سلولهاى سرطان سينه Her2 شده و

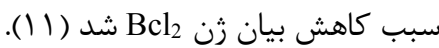

$$
\text { كايمر آيتامر - آنتى سنس }
$$

رسانش با واسطه آيتامر اليخونوكلئوتيد درمانى، خودشان را به إنه رسانش نوكلئيك اسيد درون سيتوزول سلول محدود نمى كنند

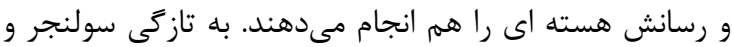

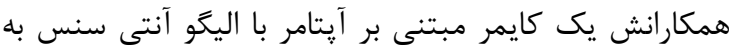

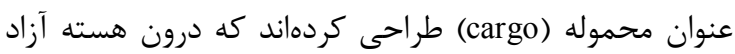
مىشود (شكل \&) (rV). اليكو آنتى سنس به كار رفته، RNA 2'-O-Me تك رشتهاى با ستون فقرات شيميايى
RNA (T) بايد به صورت اختصاصى به سلول هدف وارد شود و به به محل فعاليت خود برسد. براى رسيدن به اين اهداف، كسترش نانو

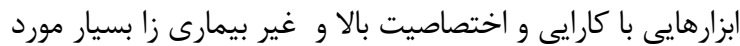
يياز است. رسانش با واسطه آيتامر پتانسيل جديدى در اين رابطه

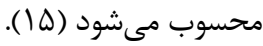

SiRNA - كايمر آيتامر

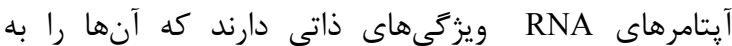
بلوكهاى ساختمانى بالقوه براى ساخت پايين به بالا نانوذرات

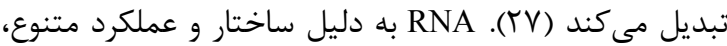
در ساختن منحصربه فرد است. يك ساختار بزركتر دو يا سه

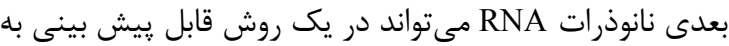

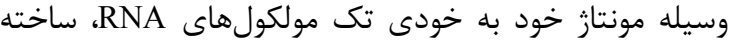
شود. آيتامرهاى RNA و RiRNA به طور موفق به صورت غيركووالانسى براى ساخت يك كايمر جهت رسيدن به به رسانش هدفمند SiRNA، افزايش پتانسيل تداخل RNA و كم كم كردن عوارض جانبى ناخواسته، به هم متصل شدهاند (ها). مولكولهاى SiRNA دويلكس هاى RNA حدود

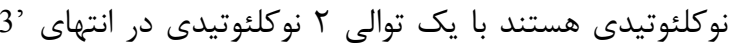

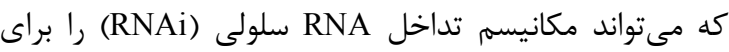
خاموش كردن زن اختصاصى به راه بيندازد. مثالهاى زير جندين روش مختلف خودبازآرايى آتِامر و و درمان هدفمند را بيان مى كند.

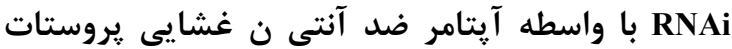

(PSMA)

آنتىرن غشايى اختصاصى يروستات (PSMA) يك يروتئين عبور كننده از غشا است كه در مراحل اوليه و متاستاز سرطان يروستات به ميزان بالا روى سطح سلول و غشاى اندوتليوم بيان مىشود، ولى روى سطح سلول هاى ايىتليال طبيعى

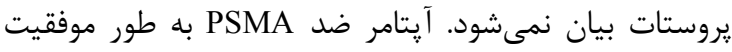
آميزى براى رسانش هدفمند siRNA به سلولهاى هدف إنتامر ضدان سرطانى به كار برده شد (•r). در مطالعهاى كه توسط خو همكارانش انجام گرفت، آتِامرهاى PSMA A9 به صورت

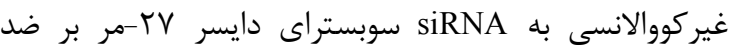
GAPDH يا لامين A/C با استفاده از يك استراتزى مدولار

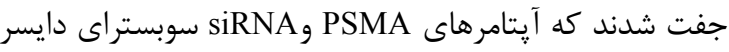
به طور جداكانه بيوتينه شدند و سيس با اتصال به يك يل يل استريتاويدين با هم متحد شدند ( شكل Ta (1) (1 ). 


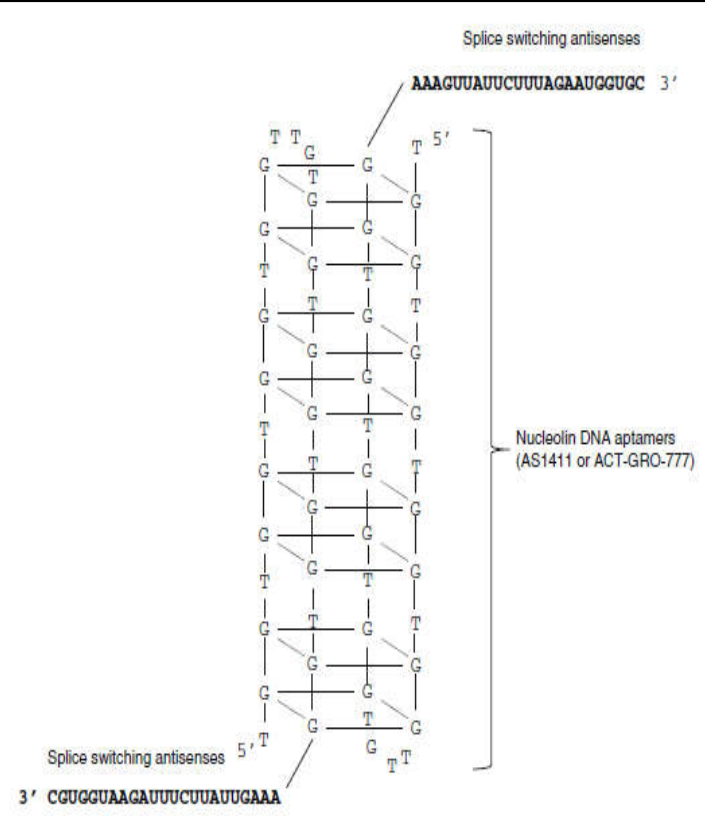

شكل F. آيتامرهاى AS1411 هسته جهارتايى ضد موازى دايمر G به وسيله اوليكونوكلئوتيدهاى spliceswitching

تحقيقات بيشتر در توسعه نانو فناورى RNA باهدف مقابله با سه جالش اصلى زير بايد انجام كيرد:

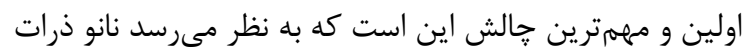

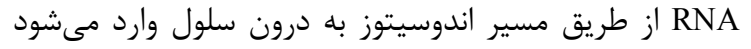
كه مىتواند به جهار نوع مختلف تقسيم شود: (1) اندوسيتوز

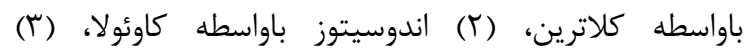

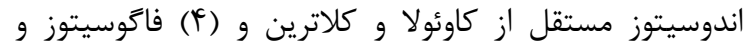
ماكرويينوسيتوز (F)

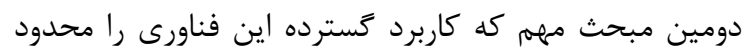
مى كند، اين است كه كيرندهاى شناختهشيده سطح سلولى مربوط به ورود به داخل سلول بسيار اندك هستند؛ بنابراين

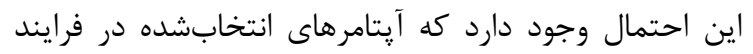
SELEX سلولى، تنها به سطح سلول اتصال يافته، اما بهطور مؤثر به سيتويلاسم سلول وارد نشوند. در اين مورد، محموله

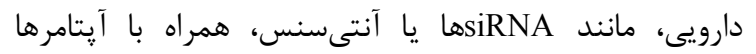
نمىتواند به جايعاه عمل خود برسد.

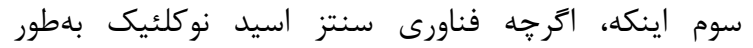
قابلتوجهى در دهه كذشته، بهبوديافته است؛ اما، هزينه توليد

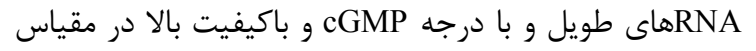
صنعتى بسيار زياد بوده و بلطور قابلتوجهى توسعه بالينى و

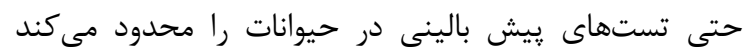

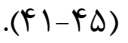

phosphorothioate تقويت كننده (enhancer) متصل مىشود تا مانع دسترسى به ماشين بيرايش شود؛ در نتيجه الكوى بيرايش mRNA هدف و

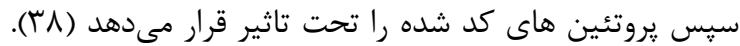

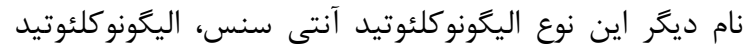
splice-switching

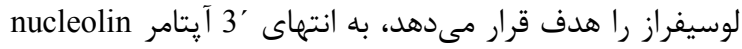

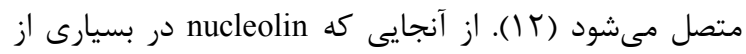

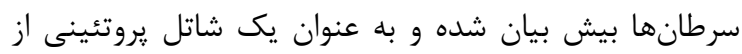

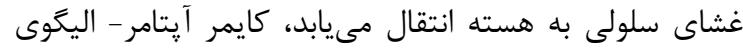

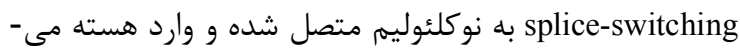

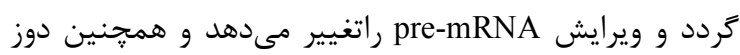
درمانى كمترى در مقايسه با اليخوى splice-switching تنها

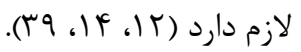

\section{نتيجهَيرى و جشممانداز آينده}

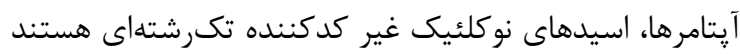

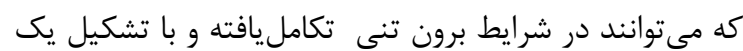

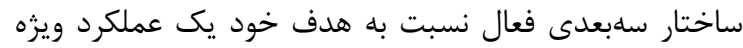

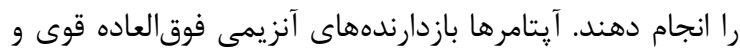

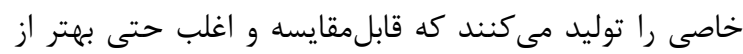

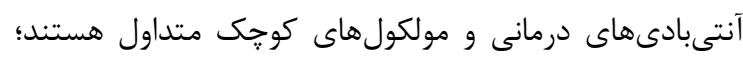

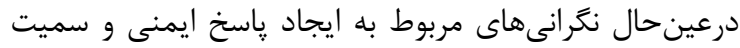

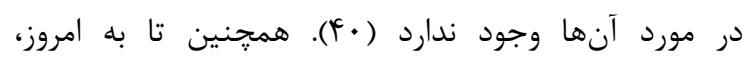

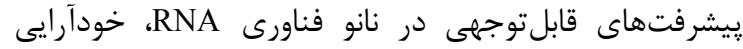

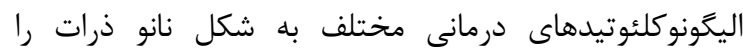

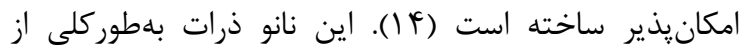

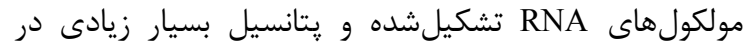

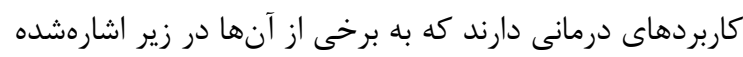

اندازه مناسب، ظرفيت קندكانه، كمترين تحريك ياسخ ايمنى

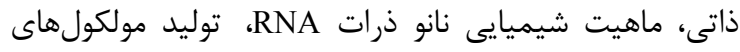
RNA

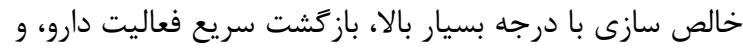

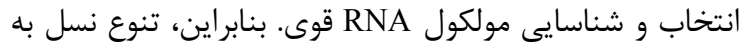
نسل در سنتز RNA حداقل است. با توجه به ماهيت شيميايى نانو ذرات RNA، مولكولهاى تزارشكر و يا كروههاى فعال

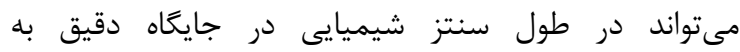
مولكول هاى RNA اضافه كردد (1) أ). 


$$
\begin{aligned}
& \text { يافت. درمجموع اين نانو ذرات مبتنى بر آيتامر كاربردهاى } \\
& \text { بيشبينى مىشود كه نانو ذرات مبتنى بر آيتامر جديد، مانند }
\end{aligned}
$$

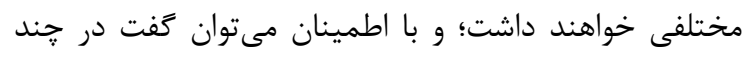

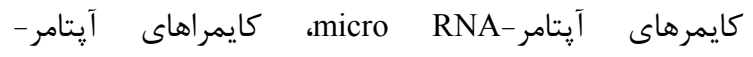

$$
\begin{aligned}
& \text { سال آينده، فناورى نانو نقش حياتى در تسريع ترجمه و و توسعه } \\
& \text { antagomir } \\
& \text { داروهاى مبتنى بر RNA ايفا خواهد كرد. }
\end{aligned}
$$

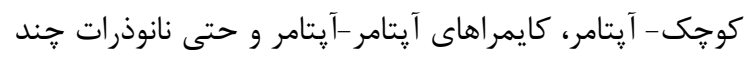

$$
\begin{aligned}
& \text { ظرفيتى آيتامر-microRNA-siRNA، بهزودى توسعه خواهي آنامد }
\end{aligned}
$$

\section{REFERENCES}

1. Hicke BJ, Stephens AW. Escort aptamers: a delivery service for diagnosis and therapy. J Clin Invest 2000; 106:92328.

2. Paris G, Kraszewski S, Ramseyer C, Enescu M. About the structural role of disulfide bridges in serum albumins: evidence from protein simulated unfolding. Biopolymers 2012; 97: 889-98.

3. Govindarajan S, Goldstein R. On the thermodynamic hypothesis of protein folding. Proc Natl Acad Sci USA 1998; 95:5545-49.

4. Ellington AD, Szostak JW. In vitro selection of RNA molecules that bind specific ligands. 1990; Nature 346:818-22.

5. Tuerk C, Gold L. Systematic evolution of ligands by exponential enrichment: RNA ligands to bacteriophage T4 DNA polymerase. Science 1990;249:505-10.

6. Lakhin AV, Tarantul VZ, Gening LV. Aptamers: problems, solutions and prospects. Acta Naturae 2013; 5: 34-43.

7. Crivianu-Gaita V, Thompson M. Aptamers, antibody scFv, and antibody Fab' fragments: An overview and comparison of three of the most versatile biosensor biorecognition elements. Biosens Bioelectron 2016;85:32-45.

8. Majumder P, Gomes KN, Ulrich H. Aptamers: from bench side research towards patented molecules with therapeutic applications. Expert Opin Ther Pat 2009;19:1603-13.

9. Dunn MR, Jimenez RM, Chaput JC. Analysis of aptamer discovery and technology. Nature Rev Chem 2017;10: 0076.

10. Sun W, Du L, Li M. Advances and perspectives in cell-specific aptamers. Curr Pharm Des 2011;17:80-91.

11. Zhou J, Rossi JJ. Aptamer-targeted cell-specific RNA interference. Silence 2010;1:4.

12. Klussmann S, ed. The aptamer handbook: functional oligonucleotides and their applications. Germany: Wiley; 2006.

13. Rossi JJ. RNA nanoparticles come of age. Acta Biochim Biophys Sin 2011;43:245-47.

14. Guo P, Coban O, Snead NM. Engineering RNA for targeted siRNA delivery and medical application. Adv Drug Deliv Rev 2010;62:650-66.

15. Zhou J, Rossi JJ. Cell-specific aptamer-mediated targeted drug delivery. Oligonucleotides 2011;21:1-10.

16. Song E, Zhu P, Lee SK. Antibody mediated in vivo delivery of small interfering RNAs via cell-surface receptors. Nat Biotechnol 2005.23:709-717.

17. Nimjee SM, White RR, Becker RC, Sullenger BA. Aptamers as therapeutics. Annu Rev Pharmacol Toxicol 2017; 57:61-79.

18. Chu TC, Twu KY, Ellington AD. Aptamer mediated siRNA delivery. Nucleic Acids Res 2006; $34: \mathrm{e} 73$

19. McNamara JO 2nd, Andrechek ER, Wang Y, Viles KD, Rempel RE, Gilboa E, et al. Cell type-specific delivery of siRNAs with aptamer-siRNA chimeras. Nat Biotechnol 2006;24:1005-15.

20. Wullner U, Neef I, Eller A, Kleines M, Tur MK, Barth S. Cell-specific induction of apoptosis by rationally designed bivalent aptamer-siRNA transcripts silencing eukaryotic elongation factor 2. Curr Cancer Drug Targets 2008; 8:554-65.

21. Dassie JP, Liu XY, Thomas GS, Whitaker RM, Thiel KW, Stockdale KR, et al. Systemic administration of optimized aptamer-siRNA chimeras promotes regression of PSMA-expressing tumors. Nat Biotechnol 2009; 27:839-49.

22. Dhar S, Gu FX, Langer R, Farokhzad OC, Lippard SJ. Targeted delivery of cisplatin to prostate cancer cells by aptamer functionalized Pt(IV) prodrug-PLGA-PEG nanoparticles. Proc Natl Acad Sci USA. 2008;105:17356-61.

23. Charbgoo F, Behmanesh M, Nikkhah M, Kane EG. RNAi mediated gene silencing of ITPA using a targeted nanocarrier: apoptosis induction in SKBR3 cancer cells, Clin Exper Pharmacol Physiol 2017;44: 24-31.

24. Mohebbi S, Behmanesh M, Nikkhah M, Tohidi Moghadam T. Apoptosis induction in glioma cells by downregulation of HIF-1 $\alpha$ gene. JMBS 2017; 9:103-10. [In Persian] 
25. Bakhtiari N, Safavi SM, Hoseinipajouh KH. Cytotoxic effects of Clusterin antisense oligonucleotides and Docetaxel on two prostate cancer cell lines. JQUMS. 2015;19: 4-10. [In Persian]

26. Bakhtiari N, Mirshahi M, Babaeipour V, Maghsoudi N. Inhibition of ackA and pta genes using two specific antisense RNAs reduced acetate accumulation in batch fermentation of E.coli BL21(DE3). Iranian J Biotechnol 2010; 8: 243-51.

27. Guo P. The emerging field of RNA nanotechnology. Nat Nanotechnol 2010;5:833-42.

28 Zhou J, Bobbin ML, Burnett JG, Rossi JJ. Current progress of RNA aptamer-based therapeutics. Front Genet. 2012;3:234.

29. Anilkumar G, Rajasekaran SA, Wang S, Hankinson O, Bander NH, Rajasekaran AK. Prostate-specific membrane antigen association with filamin A modulates its internalization and NAALADase activity. Cancer Res 2003; 63:264548.

30. Markovic I, Clouse KA. Recent advances in understanding the molecular mechanisms of HIV-1 entry and fusion: revisiting current targets and considering new options for therapeutic intervention. Curr HIV Res 2004; 2:223-34.

31. Wilen CB, Tilton JC, Doms RW. Molecular mechanisms of HIV entry. Adv Exp Med Biol 2012;726:223-42.

32. Zhou J, Li H, Li S, Zaia J, Rossi JJ. Novel dual inhibitory function aptamer-siRNA delivery system for HIV-1 therapy. Mol Ther 2008;16:1481-89.

33. Zhou J, Swiderski P, Li H, Zhang J, Neff CP, Akkina R, et al. Selection, characterization and application of new RNA HIV gp 120 aptamers for facile delivery of dicer substrate siRNAs into HIV infected cells. Nucleic Acids Res 2009;37:3094-109.

34 Thiel KW, Hernandez LI, Dassie JP, Thiel WH, Liu X, Stockdale KR, Rothman AM, et al. Delivery of chemosensitizing siRNAs to HER2 + _breast cancer cells using RNA aptamers. Nucleic Acids Res. 2012; 40:6319-37.

35. Arteaga CL, Sliwkowski MX, Osborne CK, Perez EA, Puglisi F, Gianni L. Treatment of HER2-positive breast cancer: current status and future perspectives. Nat Rev Clin Oncol 2012;9:16-32.

36. Liu W, Bulgaru A, Haigentz M, Stein CA, Perez-Soler R, Mani S. The BCL2-family of protein ligands as cancer drugs: the next generation of therapeutics. Curr Med Chem Anticancer Agents 2003;3:217-223.

37. Kotula JW, Pratico ED, Ming X , Nakagawa O, Juliano RL, Sullenger BA. Aptamer-mediated delivery of spliceswitching oligonucleotides to the nuclei of cancer cells. Nucleic Acid Ther 2012;22:187-195.

38. Bauman J, Jearawiriyapaisarn N, Kole R. Therapeutic potential of splice-switching oligonucleotides. Oligonucleotides 2009;19:1-13.

39. Soundararajan S, Wang L, Sridharan V, Chen W, Courtenay-Luck N, Jones D, et al. Plasma membrane nucleolin is a receptor for the anticancer aptamer AS1411 in MV4-11 leukemia cells. Mol Pharmacol 2009;76:984-91.

40. Nimjee SM, Rusconi CP, Sullenger BA. Aptamers: an emerging class of therapeutics. Annu Rev Med 2005;56:55583.

41. Caruthers MH. The chemical synthesis of DNA/RNA - our gift to science. J Biol Chem 2012;288:1420-27.

42. Nguyen J, Szoka FC. Nucleic acid delivery: the missing pieces of the puzzle? Acc Chem Res 2012; 45:1153-62.

43. Mukherjee S, Ghosh RN, Maxfield FR. Endocytosis. Physiol Rev 1997;77:759-803.

44. Schroeder A, Levins CG, Cortez C, Langer R, Anderson DG. Lipid-based nanotherapeutics for siRNA delivery. J Intern Med 2010;267:9-21.

45. Thiel KW, Giangrande PH. Intracellular delivery of RNA-based therapeutics using aptamers. Ther Deliv 2010;1:849-61. 